Liliya Shevchuk, Orysya Strogan and Iryna Koval

\title{
EQUIPMENT FOR MAGNETIC-CAVITY WATER DISINFECTION
}

\author{
Lviv Politechnic National University, \\ 12, Bandera str., 79013 Lviv, Ukraine \\ shevchuk_l@yahoo.com
}

Received: September 09, 2011 / Revised: October 28, 2011 / Accepted: M arch 30, 2012

(C) Shevchuk L., Strogan O., Koval I., 2012

\begin{abstract}
Push-pull vibratory electromagnetic cavitator of resonance action consists of two electromagnets, an elastic system connecting their stators and anchors, and two cavitation breakers located in the flowing liquid in the form of soundboards with holes which fluctuate in antiphase. High degree of biological disinfection of water with the productivity of approximately $3.5 \mathrm{~m}^{3} / \mathrm{h}$ at its continuous supply is provided due to the combination of magnetic and cavitation effects.
\end{abstract}

Keywords: push-pull electromagnet, stator, anchor, cavitator, cavitation, magnetic field, water, pollution.

\section{Introduction}

A wide variety of physical, chemical and integrated methods are used for industrial and domestic water purification and disinfection, however no universal method for water purification from varied pollutants of different nature has been developed yet. Most probably it is not possible, considering the variety of inorganic, organic and biological pollutions.

Particularly notable are technological processes of biological purification of water, as decisive and especially responsible for human health and health of all living beings in general, since biologically contaminated water might become the most dangerous source of biological infection of the living beings by intractable diseases like it had repeatedly occurred in the recent past during the devastating epidemics of plague, cholera, typhoid, diphtheria, etc.

Many methods and ways are known to improve and intensify physical and chemical processes during water treatment. Recently, physical methods based on treating water systems with external fields (magnetic, electric, ultrasonic, etc.) at various technological processes of purification are gaining importance. While earlier the efforts of chemists-practitioners were mainly focused on the application of high-frequency ultrasonic vibrations as the main source of cavitation disturbance phenomena in liquids [1], nowadays their attention is directed to the application of low-frequency vibrations. However, regardless of its considerable advantages high-frequency ultrasound as a method of cavitation perturbation has not yet managed to overcome the two main disadvantages, which are very high energy consumption and suitability for processing of only small discrete volumes of liquid, which impedes its wide industrial application.

That is why to solve such critical environmental problem as water purification, where the investigated liquid volumes are measured by hundred thousands of cubic meters, a new alternative ultrasonic processing technology should be developed. Hydrodynamic methods of cavitation perturbation seemed to be promising, but they appeared to be imperfect due to the insufficient intensity of cavitation field perturbation $[2,3]$.

The methods of magnetic field imposing on the water-dispersed system are often used to intensify the water purification processes [4]. In general, the use of magnetic field influence is combined with destructive methods, including oxidation, due to the intensification of particular type of chemical reactions. Thus, one of the most common oxidation methods of water treatment is wastewater disinfection with chlorine or its compounds chlorine dioxide, hypochlorites and chloramines. Sometimes, hydrogen peroxide, ozone, etc are used for this purpose. The magnetic field effect allows removing the impurities of biological origin from water, humus matter, molecular organic substances, including pesticides, etc. Here, the rate of the majority of redox reactions increases under the magnetic fields influence, which leads to the significant intensification of wastewater treatment by this method.

Thus, on the one hand the laboratory researches and industrial use practice convincingly demonstrate high efficiency of the usage of magnetic fields and cavitation phenomena in the liquids for the purpose of initiation and 
activation of various redox processes, including water treatment operations and water purification. On the other hand, it should be admitted that a simple and economical method of perturbation and stable cavitation maintenance as well as highly productive equipment for its industrial implementation are still absent.

Therefore, the researches aimed at creation of modern technologies of water treatment and water purification, improvement of existing and creation of the new methods, including the methods of magnetic-cavity water purification, capable of combining a high degree of water purification with considerable productivity, as well as equipment for implementation of such methods, remain highly relevant.

The aim of this study is to develop new efficient vibratory equipment for cavitation disturbance with stratification of magnetic field on the processed liquid, to research the peculiarities of its application for water purification and disinfection and to develop constructive and technological schemes of its industrial use.

The objects of the study were technological schemes and water treatment operations and purification systems as well as mechanisms of the influence of magnetic and cavitation phenomena and various gases on the pathogenic flora in the liquids.

The subject of the study was industrial and test equipment for the cavitation disturbance in the liquids, hydrodynamics under cavitation mixing conditions, kinetic regularities of magnetic influence on the microorganisms destruction under cavitation conditions.

It should be noted that the attempts to use the lowfrequency vibrations for perturbation of cavitational processes in the liquid were made before. Thus, description of hydrodynamic cavitators is presented in [3], where the cavitation disturbance intensifies due to the pulsations of elastic membranes, initiated by the pulsating compressed air. A pneumatic vibratory cavitator, in which the vibrational motions of the elastic cavitation breaker are provided by the pneumosource with the valving device and elastic shell installed between the plates-cavitators, is also describes here. However, vibrations of these devices are used only as auxiliary activators for cavities formation but not as a source of its disturbance, which has not led to significant improvement of hydrodynamic method of cavitation perturbation.

In [4] an attempt to combine in one device the lowfrequency cavitational processing of wastewater with the simultaneous stratification of magnetic field influence on it was made. Here the combined action of hydrocavitation and magnetic field has an energy effect on the water structure, improving its properties. As a result, under the action of redox processes in the treated water initiated by magnetic and cavitation fields, the rate of oxidation reactions increases, providing water purification. A certain limitation in application of this cavitator is its low productivity due to the fact that all processed water is supplied through small holes - disturbers of cavitation. This actually renders impossible processing of tap water in the continuous flow, reducing it to the proportional discrete, and hence, to inefficient purification. That is why this cavitator cannot be applied for industrial needs.

\section{Results and Discussion}

Push-pull vibratory electromagnetic cavitator of resonance action for cavitation disturbance in the liquids belongs to equipment for chemical and technological cavitation processes. It can be applied for water purification, disinfection of drinking water, decontamination of wastewater from chemical, food and processing enterprises from various pollutants, including biological the ones, etc.

This cavitator belongs to a group of equipment of physical and chemical methods of cavitational initiation and activation of redox reactions in the liquids by the cracking energy of a large number of cavitation bubbles in conjunction with magnetic treatment of the liquids.

Schematic diagram of cavitator for magnetic-cavity liquids processing is shown in Fig. 1. The cross section A-A (Fig. 1) of cavitator with the power lines of magnetic field (Fig. 2a), the scheme of cavitation field formation (Fig. 2b) at the liquid flowing through the tube-nozzle (Fig. 2c) are shown. The cavitator consists of two diametrically opposite electromagnets with a stator and an anchor. One of them was placed on the water supply pipe 1 and the other - on the purified water output pipe 5 (Fig. 1). For electromagnets attachment to the pipes 1 and 5 they are equipped with the body 2 , in which both the stator 3 with the coil 4 and clamp 6 with the bracket 7 are fixed. Under the stators on the sides of the water supply and output pipes anchors 10 are placed with a gap and attached to the flat soundboards 8 and 9 , made of sheet iron (Fig. 2a).

The stator 3 with the coil 4 and the anchor 10 actually form an electromagnet and the diametrically opposed electromagnets form the push-pull electromagnetic exciter of vibrations.

The soundboards 8 and 9 , attached to the anchors 10 are perpendicularly placed to the flow of the processed liquid and are interconnected with each other and with the pipes 1 and 5 through the flexible corrugations 11 . The processed liquid supply pipe 1 and the liquid output pipe 5 form the immobile body and the soundboards 8 and 9, which placed between them, with the corrugations 11 form the working chamber. 

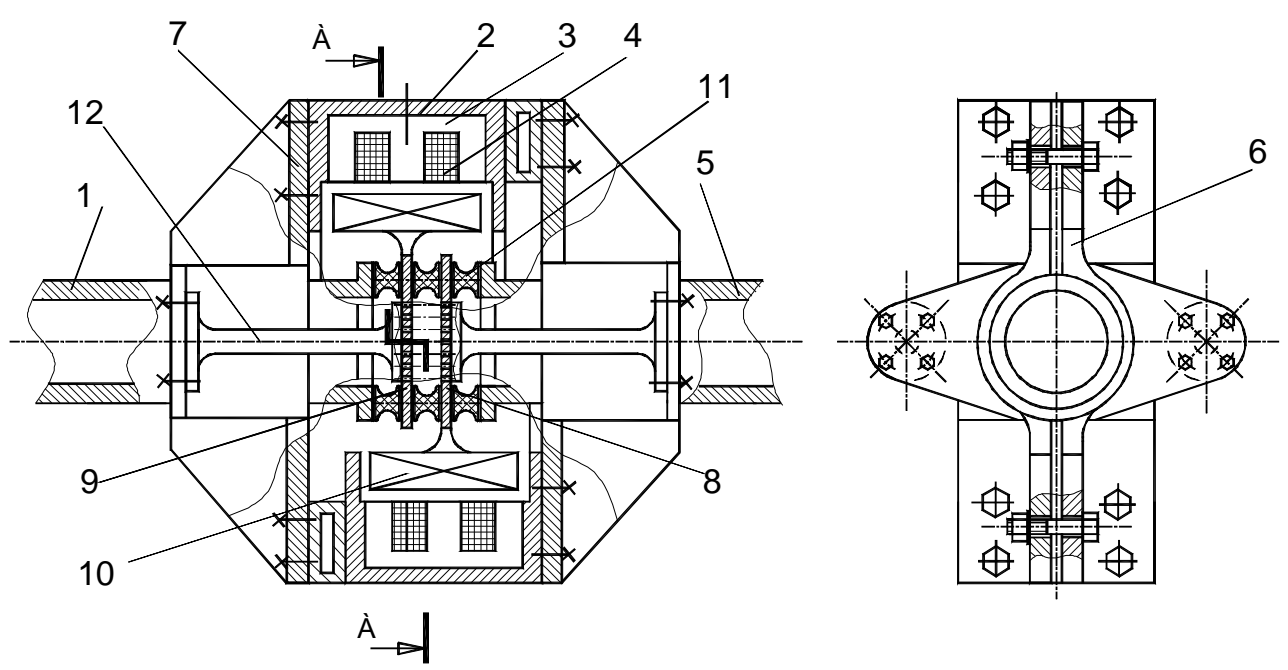

Fig. 1. Schematic diagram of push-pull vibratory electromagnetic cavitator of resonance action for magnetic-cavity liquids processing

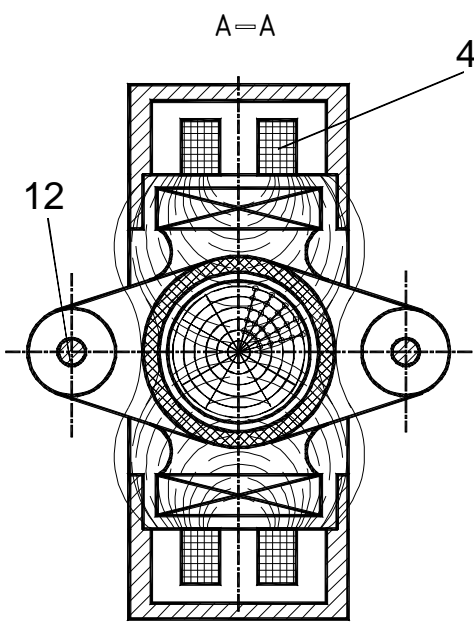

a)

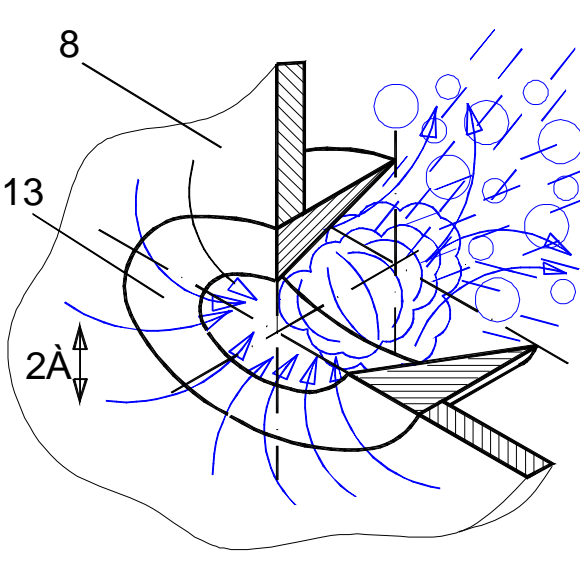

b)

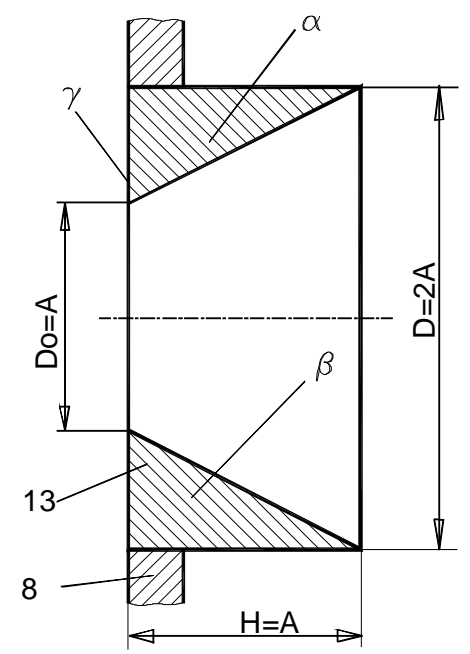

c)

Fig. 2. Scheme of the physical effects on the processed liquid: magnetic field (a); cavitation field (b) and the ratios of nozzle-injector sizes (c)

The planes of the soundboards located in the pipe working chamber space have evenly made holes for the processed liquid flowing. To prevent axial displacement and rotation each of the soundboards 8 and 9 are fixed by two console rod stabilizers 12 , one flange of which is attached to the body 2, and another - to the fragments of the soundboards outside the pipe plane. The stabilizers 12 together with the flexible corrugations 11 act as agents of elastic system of electromagnetic vibrations exciters. Hence, they should have such rigidity that the eigenfrequency of fluctuations of the soundboards 8 and 9 , attached to them, was as close as possible to the frequency of voltage supplied to the coil electromagnets, i.e. the work of push-pull electromagnetic exciter of vibrations was performed in the resonant regime or in the mode close to it. Maximum coefficient of efficiency and minimum loss of energy of the work of push-pull electromagnetic exciter of vibrations are reached in this mode.

To intensify the disturbance of cavitation cavities at the processed liquid flowing through the soundboards 8 and 9 the nozzle-injectors 13 with cylindrical outer $\alpha$ and conical inner $\beta$ surfaces were pressed in their holes (Fig. $2 \mathrm{~b})$. The diameter of the cylindrical surface $D_{c}=2 A$ and 
the maximum radius of the conical inner surface $R=2 A$ is equal to the swing, i.e. the double value of the fluctuations amplitude $A$ of the soundboard. The nozzle height $H$ is equal to the fluctuations amplitude $A$. The internal conical surface $\beta$ forms a hole for the liquid flowing in the intersection with the butt-end plane $\gamma$ of the nozzleinjectors 13 . The diameter of the hole is equal to $D_{0}=A$. This hole of the nozzle 13 is aimed in the direction opposite to the direction of the processed liquid flow. The distance between the adjacent holes in the soundboards is equal to the double value of the fluctuations amplitude, i.e. $k=4 A$ (Fig. 2c).

The device for magnetic-cavity liquid treatment works as follows. The processed liquid is supplied through the pipe 1 under slight pressure or by gravity. Simultaneously, alternating voltage is supplied to the windings 4 of coils 3 of the electromagnets. The electromagnets simultaneously attract to the stators their anchors with the attached soundboards 8 or 9 with the holes, bending the elastic rods of the stabilizers 12 and flexible corrugations 11, which form the elastic system. In the first half-period of alternating voltage feeding of electromagnets coils the anchors 10 , overcoming the resistance of the elastic systems are attracted to the appropriate stators 3 and in the second half-period - when alternating voltage of the opposite sign is supplied to the windings 4 of coils, they move away from the stators under the influence of elastic forces. Whipping and flexibility of stabilizers 12 and flexible corrugations 11 is designed in such a way that they render impossible striking of anchor 10 with the stator 3 . Alternate attraction of anchors to the stators coils is transformed into planeparallel directed fluctuations of opposite phase of two elastically installed fluctuating masses, each of which is formed of the soundboard 8 or 9 and the anchor 10. These fluctuations occur with some estimates of amplitude and frequency, which are equal to the voltage supply frequency to the coils of push-pull electromagnetic exciter of vibrations (usually $50 \mathrm{~Hz}$ ).

During the antiphased plane-parallel displacements the sharp edges of the holes of the soundboards 8 and 9 cross the continuous flow of the processed liquid. The maximum instantaneous speed at which the soundboard crosses the liquid flow reaches $8-9.5 \mathrm{~m} / \mathrm{s}$ at the recommended fluctuations amplitude of the soundboard of $2.5-3 \mathrm{~mm}$ and at the frequency of $50 \mathrm{~Hz}$. The speed of relative displacement of the two neighboring soundboards, which fluctuate in antiphase, is more than two times higher, i.e. $16-19 \mathrm{~m} / \mathrm{s}$. This is enough for perturbation the air cavitation cavities by the sharp edges of holes in soundboard always presented cavitation nuclei in the liquid. The pressure inside the cavity rapidly increases at displacement of the air cavities in the formed hydrodynamic cavitation field of the processed liquid, increasing the cavities volume, which consequently leads to creation of a cavitation field with shock wave impulses (Fig. 2b). Influence of shock waves impulses on the cavitation nuclei present in the liquid leads to instantaneous nucleation, expansion and further destruction of cavitation bubbles. Uniformity of cavitation field intensity throughout the area of the cross-section of the liquid supply pipe 1 , i.e., uniformity of the cavitation process is provided by the uniform location of holes in the soundboards 8 and 9.

At the same time, work of each electromagnet, which is focused on the fluctuations of anchors 10 with soundboards 8 and 9 , is accompanied by the formation of alternating magnetic flows with significant induction gradient by their stators 3 with windings 4 . Being summarized they cross the working chamber filled with the flowing treated liquid (Fig. 2a) providing a magnetic treatment of the liquid. Thus, due to symmetrical position of the cavitation perturbation soundboards the liquid is twice subjected to the cavitation treatment and once to the magnetic one.

After the action of inhomogeneous magnetic field on the water its molecules become quasistable, leading to lower energy links between the water molecules. Consequently, the processed water can be seen as something other than an ordinary water-solvent, although with close physical and chemical properties. By its dissociation capacity water under the influence of magnetic field is close to aprotic solvents.

Such changes cause its further impact on the physical and chemical processes whose kinetics depends on the hydrogen bonds strength of water as a solvent and its dissociation capacity as a reagent.

According to the hypothesis of V. Antonchenko [4], braking of protons is the cause of hydrogen bonds weakening between water molecules in a transverse magnetic field. Moreover, here the proton together with the hydroxyl $\mathrm{OH}$-group forms the water molecule with different energy state in the magnetic field than without it. The proof of the above stated is the increase of the dielectric permeability of aqueous solutions due to magnetic processing [4]. After double cavitation and magnetic treatment the liquid through the output pipe 5 is exported to desilting, purification from inactivated sludge sediment and future intended use.

Adjustment of quality of the processed liquids in the device for magnetic-cavity treatment is performed via regulation of intensity in the liquids of the cavitation field, which is dependent on the amplitude $\mathrm{A}$ of cavitation perturbation soundboards oscillations and the diameter $D_{0}$ of the holes for liquid flowing. Oscillations amplitude of the soundboards and intensity of the magnetic field is regulated by changing the value of the current supplied to the electromagnets coils 4 . 
Calculation of elasticity of the vibratory systems, power of the electromagnets and their structural elements (form and size of electromagnets, cross section and number of turns on coils, etc.) is carried out according to the conventional calculation methods for resonant vibratory machines with magnetic actuator [5].

Magnetic-cavity influence on the liquid medium by the described effects allows achieving a significant intensification of chemical transformations in water flows. Thus, the experiments conducted using the model setup demonstrated lower content of calcium and magnesium salts in the technically contaminated water by 22 percent. Analysis of the water which was processed for $20 \mathrm{~min}$ using the magneto-cavity device showed the growth of its oxidation by 180 percent and 20 times reduction of growth rate of pathogenic bacteria colonies. To some extent these data coincide with the results of studies of other authors [4].

\section{Conclusions}

The main advantages of push-pull vibratory electromagnetic cavitator of resonance action for magnetic-cavity processing of liquids as compared to the well-known ones are its high performance, suitability for processing of large amounts of liquids in continuous flow while ensuring uniformity of liquids treatment with high coefficient of efficiency, and design simplification due to the two-function use of the electromagnets - for driving the cavitation perturbation factors to create the cavitation field and as sources of magnetic flows of high induction gradient for magnetic treatment of liquids.

Two independent physical effects have been combined. Cavitation and magnetic fields are both aimed to change the structure and the properties of the treated liquids and to intensify redox processes and initiate chemical reactions in the liquids.

Vibratory electromagnetic cavitators of resonance action are promising equipment for water treatment, which allow simultaneous disinfection of water and oxidation of pollutants. The specific feature of magneticcavity effect on the biological contamination of water is the number of simultaneous actions of physical and mechanical factors: shock waves, cumulation, flutter, rectified diffusion and vibroturbulence, and magnetic field. In addition, due to the destruction of cavitation bubbles active chemicals are formed: hydroxyl radicals, ozone, hydrogen peroxide, etc. In essence, this technology is the combined method of water treatment. It can be predicted that combination of physical and chemical factors of hydrodynamic vibrocavitation is likely create most favorable conditions for active inactivation of harmful microorganisms in water.

\section{References}

[1] Marhulis M.: Osnovy Zvukochimiyi (Khimicheskie Reakcii v Akustycheskyh polyah). Vycsh. Shkola, Moskwa 1984.

[2] Vitenko T.: Gidrodynamichna Kavitaciya u Masoobminnyh, Khimichnyh i Biologichnyh Procesah., TDTU im. I. Puluja, Ternopil 2009.

[3] Vitenko T.: Doctoral thesis, Lviv Polytechnic Nats. Univ., Lviv 2010.

[4] Silin R., Baran B. and Gordeev A.: Vlastyvosti Vody ta Suchasni Sposoby ii Ochystchennya., Khmel. Nats. Univ., Khmelnytskiy 2009.

[5] Lanets O.: Vysokoefektyvni Mishrezonansni Vibratsiyni Mashyny z Elektromagnitnym Pryvodom. NU "Lvivs'ka Polytechnika", Lviv 2008.

\section{ОБЛАДНАННЯ ДЛЯ МАГНІТНО- КАВІТАЦЙНОГО ЗНЕЗАРАЖЕННЯ ВОДИ}

Анотація. Двотактний вібраційний електромагнітний кавітатор резонансної дї складається із двох електромагнітів, пружної системи, щзо з'єднує їх статори та якорі, і розташованих у протічній рідині збурювачів кавітачії у вигляді двох дек із отворами, що коливаються у противофазі. Завдяки поєднанню магнітного та кавітаційного впливів забезпечує високу ступінь біологічного знезараження води при ії неперервному подаванні із продуктивністю приблизно $3,5 \mathrm{~m}^{3} / 2 о д$.

Ключові слова. електромагніт двотактний, статор, якір, кавітатор, кавітаиія, магнітне поле, вода, забруднення. 